\title{
Reduction, methylation, and translocation of arsenic in Panax notoginseng grown under field conditions in arsenic-contaminated soils
}

\author{
Jie Ma ${ }^{\mathrm{a}, \mathrm{b}}$, Yanhua Mi ${ }^{\mathrm{a}, *}$, Qiwan $\mathrm{Li}^{\mathrm{a}}$, Lu Chen ${ }^{\mathrm{a}}$, Lijuan Du ${ }^{\mathrm{a}}$, Lizhong He ${ }^{\mathrm{a}}$, Mei Lei ${ }^{\mathrm{b}}$ \\ a Agri-Food Quality Standard and Testing Technology Institute, Yunnan Academy of Agricultural Sciences, Kunming, 650221, PR China \\ b Center for Environmental Remediation, Institute of Geographic Sciences and Natural Resources Research, Chinese Academy of Sciences, Beijing 100101, PR China
}

\section{H I G H L I G H T S}

- Arsenic(V) could be reduced and subsequently methylated in Panax notoginseng.

- The reduction and methylation of As in the root were promoted by low As toxic stress, but were impeded by high As toxic stress.

- The translocation of total As, As(III), and MMA from the root to the rhizome was a response to As toxic stress.

\section{GRA P H I C A L A B S T R A C T}

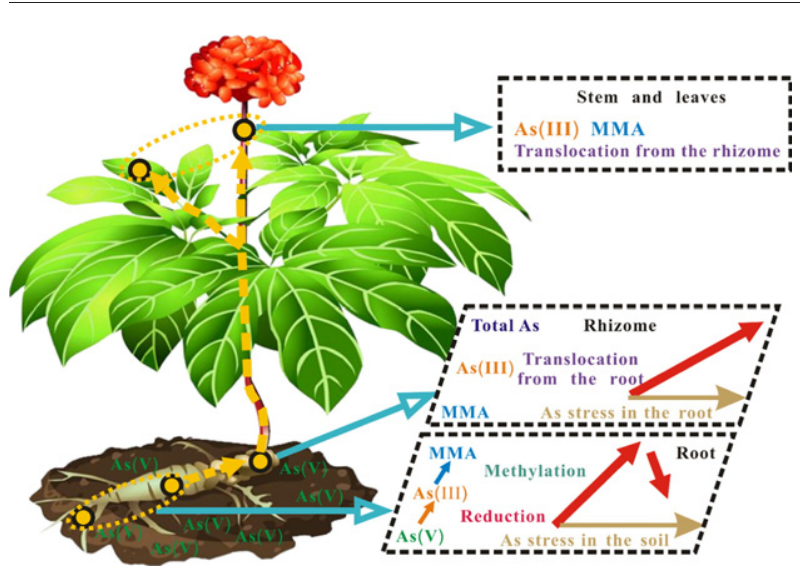

\section{A B S T R A C T}

Variations in arsenic (As) species in Panax notoginseng grown under field conditions remain understudied compared with those under greenhouse conditions. In the present study, soil and plant samples were collected from Wenshan Zhuang and Miao Autonomous Prefecture, Yunnan Province, which is the main production area of $P$. notoginseng in China, to identify As species in the soil and plant tissues and further assess effect of As toxic stress on As transformation and translocation in P. notoginseng. The results showed that arsenate $(\mathrm{As}(\mathrm{V}))$ was almost exclusively identified in the soil, while arsenite ( $\mathrm{As}(\mathrm{III})$ ) and monomethylarsonic acid (MMA) were detected in high proportions in plant tissues, suggesting that $\mathrm{As}(\mathrm{V})$ could be reduced and subsequently methylated in the plant body, mainly in the root. The reduction and methylation of As in the root of P. notoginseng were promoted by low As toxic stress, but were impeded by high As toxic stress. Arsenic(III) and MMA could rapidly translocate upwards in P. notoginseng. In addition, the translocation of total As, As(III), and MMA from the root to the rhizome was a response to As toxic stress, and the translocation rate increased with the increasing As concentration in the taproot. This study provides new insights into the detoxification mechanism of $P$. notoginseng grown in Ascontaminated soils and the control of As during cultivation.

(c) 2016 Elsevier B.V. All rights reserved.

\footnotetext{
* Corresponding author.

E-mail address: zhoumiqu@163.com (Y. Mi).
}

\section{Introduction}

Panax notoginseng is a perennial herb that has been used in traditional Chinese medicine for more than 600 years (Zhao, 2015). The herb has various active constituents including saponins, dencichines, flavonoids, 
and polysaccharides and has multiple medicinal effects, such as lowering blood pressure, preventing blood clot, formation and atherosclerosis, protecting neurons, and alleviating pain ( $\mathrm{Ng}, 2006)$. Therefore, it has been traditionally used for the treatment of cardiovascular diseases, cerebral vascular disease, inflammation, trauma, and hemorrhage (Yan et al., 2012).

The main production area of $P$. notoginseng in China is Wenshan Zhuang and Miao Autonomous Prefecture, which accounts for $98 \%$ of the total production in China (Guo et al., 2010). P. notoginseng produced in this area is of high quality and exported to 14 countries, providing economic benefits to local residents (Guo et al., 2010). However, arsenic (As) concentrations in the soils of this production area are elevated due to high background levels, frequent mining activities (RamirezAndreotta et al., 2013), and the large-scale use of As based pesticides and fertilizers (Williams et al., 2007). The elevated As concentrations negatively affect the active constituents of $P$. notoginseng, the expansion of the cultivated area, and continuous cropping (Lin et al., 2015).

Arsenic is a ubiquitous trace metalloid and is found in virtually all environmental media, especially in the soil (Fitz and Wenzel, 2002), while the soil-plant transfer of As is one of the principal pathways of human exposure to As (Tong et al., 2014). A previous study in Wenshan Zhuang and Miao Autonomous Prefecture demonstrated that As concentrations in $P$. notoginseng exceed the national standard $\left(<2 \mathrm{mg} \mathrm{kg}^{-1}\right.$ ) (Yan et al., 2012). It is known that plants tend to minimize As uptake and promote its translocation to aboveground parts (McGrath and Zhao, 2003). However, the high range of transfer factors in $P$. notoginseng (0.21-10.44 for leaf/main root and $1.30-8.25$ for leaf/stem) may imply some different mechanisms of As accumulation and translocation in this plant species (Yan et al., 2012).

Arsenic interferes with plant metabolism, leading to disorders at various organizational levels and inhibiting plant growth (Marin et al., 1993; Meharg, 1994). To decrease the deleterious effect, plants transform As species to mobile As from one tissue to another. The transformation and underlying mechanisms have been well documented in various plant species, including rice, tomato, and Pteris vittata (Burlo et al., 1999; Ma et al., 2001; Su et al., 2010; Tu et al., 2003; Wang et al., 2002). Arsenite ( $\operatorname{As}(\mathrm{III}))$ is the predominant As species (>80\%) in the xylem sap of Pteris vittata when growth in media supplemented with arsenate $(\mathrm{As}(\mathrm{V}))$ (Su et al., 2010), suggesting that the latter $\mathrm{As}(\mathrm{V})$ is reduced in the root cells before the loading to xylem and translocation to other plant parts (Kumar et al., 2015). After reduction, As(III) is detoxified through the complex formation with thiol-rich peptides (Liu et al., 2010) or glutathione (GSH) (Bleeker et al., 2006; Huang et al., 2008; Tripathi et al., 2007), leading to low efflux or long-distance translocation in the plant body (Kumar et al., 2015).

Methylation is another pathway that relieves As toxicity in organism. It has been identified in marine organisms (Kaise and Fukui, 1992) and has been increasingly reported in terrestrial plants (Kuehnelt et al., 2000; Wei et al., 2015). Organic As, including monomethylarsonic acid (MMA) and dimethylarsinic acid (DMA), is translocated faster from the root to the shoot compared with inorganic As (Li et al., 2009; Raab et al., 2007), while the hypotoxicity of organic As has a low effect on plant growth (Ravenscroft et al., 2009; Schoof et al., 1999).

Reduction and methylation of $P$. notoginseng grown in Ascontaminated soils affect As accumulation and translocation, and consequently As phytotoxicity. The accumulation of As species and stress responses have been investigated in $P$. notoginseng grown in pots under greenhouse conditions (Lin et al., 2015; Yan et al., 2012), however, it remains difficult to accurately describe the reduction, methylation, and translocation of As in P. notoginseng grown under field conditions in As-contaminated soils. Therefore the aim of this study was to investigate the reduction, methylation, and translocation of As in $P$. notoginseng grown under field conditions in soils containing variable levels of As. As species, including As(III), As(V), MMA, and DMA, in the soil and plant tissues were analyzed to assess effect of As toxic stress on As transformation and translocation in P. notoginseng.

\section{Materials and methods}

\subsection{Sample collection and preparation}

The study sites, main planting areas of P. notoginseng, are in Yanshan, Wenshan, and Maguan counties, located in Wenshan Zhuang and Miao Autonomous Prefecture, Yunnan Province, China (Fig. 1). This area is 1000-1600 $\mathrm{m}$ above the sea level and has a typical subtropical climate with an average annual temperature of $19{ }^{\circ} \mathrm{C}$ and rainfall of $779 \mathrm{~mm}$ (Cui and Lei, 2002). Several metal mines are embedded in the planting area of $P$. notoginseng (Fig. 1). Within the sampling region, one synthesized species of $P$. notoginseng was planted in plots with $10 \mathrm{~cm}$ intrarow and $12.5 \mathrm{~cm}$ or $15 \mathrm{~cm}$ inter-row spacing (Cui and Lei, 2002). The plants were grown for two years before sampling. The sampling sites covered the main planting area of $P$. notoginseng to ensure the samples to be representative.

Ten soil samples attached to plant roots $(<10 \mathrm{~cm}$ distance between soil and root) were collected at a depth of $0-20 \mathrm{~cm}(20 \mathrm{~cm}$ roughly equaled to the longest root depth.) along with the corresponding $P$. notoginseng plants. The samples were placed with ice pack, transported to the laboratory, and pretreated immediately to minimize the change of As species. The stones and plant debris in the soil samples were removed by hand sorting. Plant samples were washed thoroughly with running tap water, followed by three rinses with deionized water. Additionally, the roots were washed with $10 \mathrm{mmol} \mathrm{L}^{-1} \mathrm{CaCl}_{2}$ to remove any adsorbed ions (Wei et al., 2015). Each plant sample was divided into fibrous root, taproot, rhizome, stem, and leaves. Root samples were divided based on morphology. Gracile fibrous root was cut from taproot and torose rhizome with dormant bud was divided from the top of taproot. Both soil and plant samples were freeze-dried and then ground using a mixer mill with steel grinding chamber (MM400, Retsch, Germany) to produce a fine powder $(<0.074 \mathrm{~mm}$ particle size of soil samples; $<0.15 \mathrm{~mm}$ particle size of plant samples) for total As and As species analysis.

\subsection{Total As in soil and plant}

Soil samples ( $0.2 \mathrm{~g}$ of fine powder) were digested using $\mathrm{HNO}_{3}-\mathrm{H}_{2} \mathrm{O}_{2}$ (USEPA 3050B) in $50 \mathrm{ml}$ conical flasks, while plant samples ( $0.5 \mathrm{~g}$ of fine powder) were digested using concentrated $\mathrm{HNO}_{3}-\mathrm{HClO}_{4}$ in $50 \mathrm{~mL}$ conical flasks. Digested soil and plant samples were transferred into $50 \mathrm{~mL}$ volumetric flasks and brought to a final volume of $50 \mathrm{ml}$ using Milli-Q water. Arsenic concentrations in the extracts were analyzed using atomic fluorescence spectrometry (AFS-9800, KCHG, China). The recoveries of determined As in certified soil (GBW07307) and plant (GBW07603) reference materials were $92.3 \pm 3.2 \%$ and $106.7 \pm 9.3 \%$, respectively.

\subsection{Arsenic species in soil and plant}

Different As species were extracted from the soil and plant samples as described by Pizarro et al. (2003). Briefly, a $10 \mathrm{ml}$ aliquot of the extraction solution ( $1 \mathrm{~mol} \mathrm{~L}^{-1}$ phosphoric acid, with or without a standard As species solution) was added to $0.5 \mathrm{~g}$ soil sample, heated at $120^{\circ} \mathrm{C}$ for $2 \mathrm{~h}$, and then centrifuged for $15 \mathrm{~min}$ at $2000 \mathrm{~g}$-force. The extract was reserved, and the residue was re-extracted twice following the same procedure. The three extracts were mixed and filtered through a $0.22 \mu \mathrm{m}$ membrane filter. The mixture was diluted 5 -fold with $30 \mathrm{mM}$ phosphate buffer ( $\mathrm{pH}$ 6.0), and analyzed for As species.

Approximately $1-2 \mathrm{~g}$ of plant samples were placed in centrifuge tubes with $5 \mathrm{ml}$ of 1:9 methanol/water (with or without a standard As species solution). The tubes were placed in a shaking incubator at $25^{\circ} \mathrm{C}$, shaken at $180 \mathrm{rpm}$ for a $1 \mathrm{~h}$, and transferred to an ultrasonic focalized bath at $50{ }^{\circ} \mathrm{C}$ for $1 \mathrm{~h}$, and then centrifuged for $15 \mathrm{~min}$ at $2000 \mathrm{~g}$ force. The extracts were reserved, while the residues were reextracted twice following the same procedure. The three extracts 


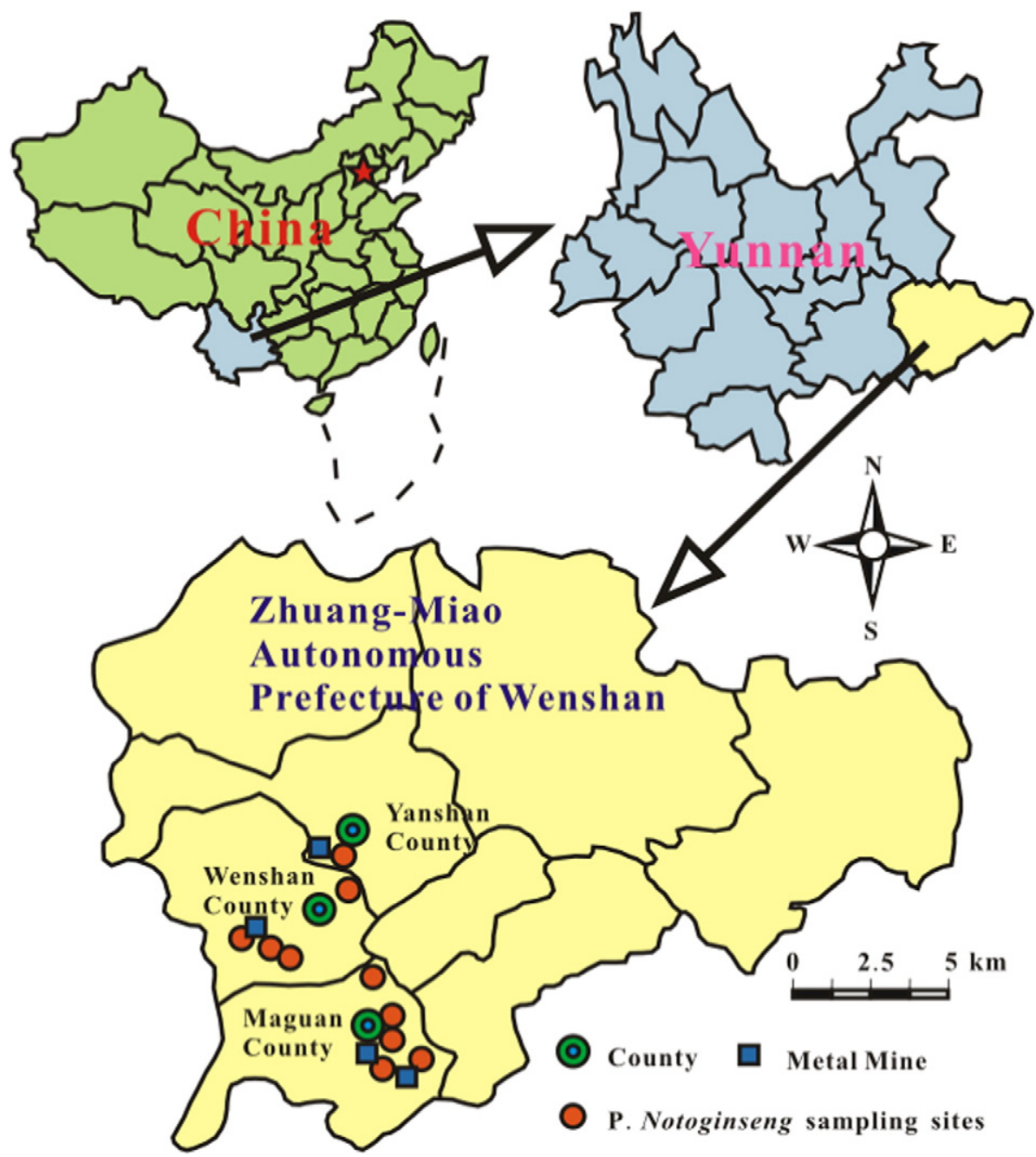

Fig. 1. Sketch map of sampling sites, located in Wenshan Zhuang and Miao Autonomous Prefecture, Yunnan Province, China.

were mixed and filtered through a $0.22 \mu \mathrm{m}$ membrane filter and subsequently analyzed for As species.

Arsenic species was determined by high performance liquid chromatography hydride generation atomic fluorescence spectrometry (HPLC-HG AFS) (PSA-10.825, PS Analytical, UK). Arsenic species were separated using anion exchange chromatography column (PRP-X100, Hamilton, USA) and a guard cartridge system (SAX, Phenomenex, USA), using $15 \mathrm{mM}$ phosphate buffer ( $\mathrm{pH}$ 6.0) as a mobile phase at a flow rate of $1.0 \mathrm{ml} \mathrm{min}{ }^{-1}$. The recovery of standard additions of $\mathrm{As}(\mathrm{III})$ and $\mathrm{As}(\mathrm{V})$ in soil and plant samples were higher than $87.9 \%$ and $85.3 \%$, respectively, showing that the As species change was not obvious. The limits of detection of As(III), DMA, MMA, and As(V) in the extracted solution were $0.4 \mu \mathrm{g} \mathrm{L}-1,0.5 \mu \mathrm{g} \mathrm{L}^{-1}, 0.5 \mu \mathrm{g} \mathrm{L}^{-1}$, and $1.0 \mu \mathrm{g} \mathrm{L}^{-1}$, respectively.

Total As and As species in the soil and the plant were performed in triplicate, with the relative standard deviations of total As and As species less than $7.2 \%$ and $23.5 \%$, respectively. The average values were used in this study. Data analysis and plotting were carried out using Origin 8.6.

\section{Results and discussion}

\subsection{Total As and As species in the soil}

Concentrations of total As and As species, proportions of As species, and extraction efficiencies of soil samples are summarized in Fig. 2. Concentrations of total As and phosphoric acid-extracted As (the sum of
As(III) and As(V)) in soil samples ranged between $10.24 \mathrm{mg} \mathrm{kg}^{-1}$ and $90.84 \mathrm{mg} \mathrm{kg}^{-1}$ with an average of $33.56 \mathrm{mg} \mathrm{kg}^{-1}$ and between $6.59 \mathrm{mg} \mathrm{kg}^{-1}$ and $39.16 \mathrm{mg} \mathrm{kg}^{-1}$ with an average of $14.24 \mathrm{mg} \mathrm{kg}^{-1}$, respectively (Fig. 2), showing a range in the study. Arsenic(V) was the major species (>95\%) in the soil, while the average proportion of

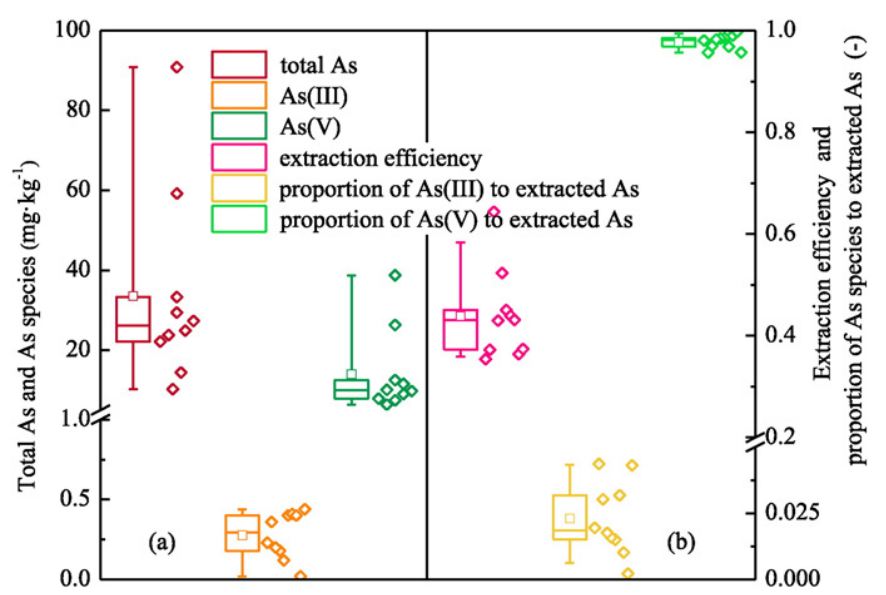

Fig. 2. Box-Whisker plot of concentrations of total As and As species (a), proportions of each species to extracted As (b) and extraction efficiencies (b) of soil samples $(n=10)$. Diamonds represent data points and squares represent the average values. 
As(III) was less than 5\% (Fig. 2), due to As(III) oxidation by Fe/Mn minerals in the soil (Campbell et al., 2006; Tufano et al., 2008). Organic As was not been detected in this study, similar to t a previous study on mining soil, with As concentrations of $32-345 \mathrm{mg} \mathrm{kg}^{-1}$ (Wei et al., 2015). Arsenic species as a function of total As estimates (extraction efficiency) ranged between $35.4 \%$ and $64.4 \%$ (Fig. 2). The phosphoric acid-extracted As included non-specifically-sorbed As, specifically-sorbed As, and As associated with amorphous and poorly-crystalline (hydr)oxides (Ma et al., 2015; Wenzel et al., 2001). These fractions were incompact and absorbable, and thus $\mathrm{As}(\mathrm{V})$ was identified as the major species absorbed by $P$. notoginseng.

\subsection{Total As and As species in plant tissues}

Concentrations of total As and As species, the proportions of As species and extraction efficiencies of $P$. notoginseng samples are summarized in Fig. 3. Overall, the average As concentration gradually decreased with an order of fibrous root $>$ rhizome $>$ taproot $\sim$ leave $>$ stem with average values of $2.10 \mathrm{mg} \mathrm{kg} \mathrm{kg}^{-1}, 0.97 \mathrm{mg} \mathrm{kg}{ }^{-1}$, $0.71 \mathrm{mg} \mathrm{kg}^{-1}, 0.70 \mathrm{mg} \mathrm{kg}^{-1}$, and $0.48 \mathrm{mg} \mathrm{kg}^{-1}$, respectively (Fig. 3). The high As concentrations in the fibrous root suggested that it readily absorbs As relative to taproot, while the low As concentrations in the aboveground parts showed that the upward translocation of As was lower in $P$. notoginseng grown under field conditions compared with
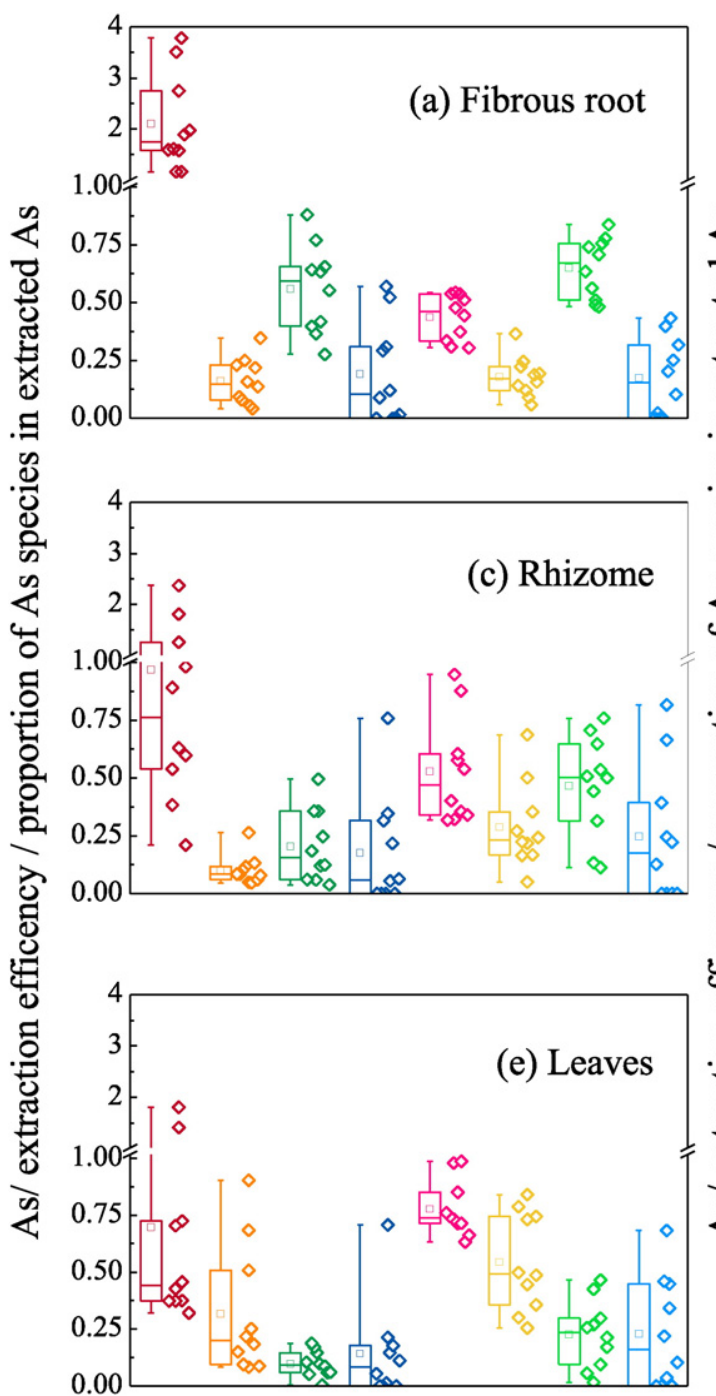

those grown in pots (Lin et al., 2015; Yan et al., 2012). The absorbedAs tended to concentrate in the rhizome and was not translocate to the aboveground parts to a great extent. Due to the high concentration disparity of As between soil and plant samples, As enrichment factors (regardless the biomass) in different tissues of $P$. notoginseng were less than 0.08 .

Arsenic(III), As(V), and MMA were identified in plant samples, while DMA was not detected. The extraction efficiencies of As species varied between the different plant tissues, ranging between $43 \%$ and $78 \%$ (Fig. 3). Although the reagent (water/methanol) was an efficient extraction (Pizarro et al., 2003; Zhao et al., 2015), low extraction efficiencies, shown in previous studies (Ruiz-Chancho et al., 2008; Sousa-Ferreira et al., 2010; Wuilloud et al., 2004), were observed in the extraction of this study. Regardless of As concentration in the soil, a part of As is stored in the cell walls (Feng et al., 2015; Lin et al., 2015). Perennial herbs grown under field conditions have thicker cell walls compared with those grown in pots, leading to low extraction efficiencies. The extractable As is possibly hosted in the cytoplasm and cell organelles that take part in its metabolism.

As mentioned above, based on the $\mathrm{H}_{3} \mathrm{PO}_{4}$-based extraction, As in the soil was found predominantly as As(V). However, As(III) was identified in the fibrous root and taproot, and the average proportion in the extracted As was roughly 20\% (Fig. 3). It indicated that absorbed $\mathrm{As}(\mathrm{V})$ from the soil was reduced in the roots of $P$. notoginseng (Kumar

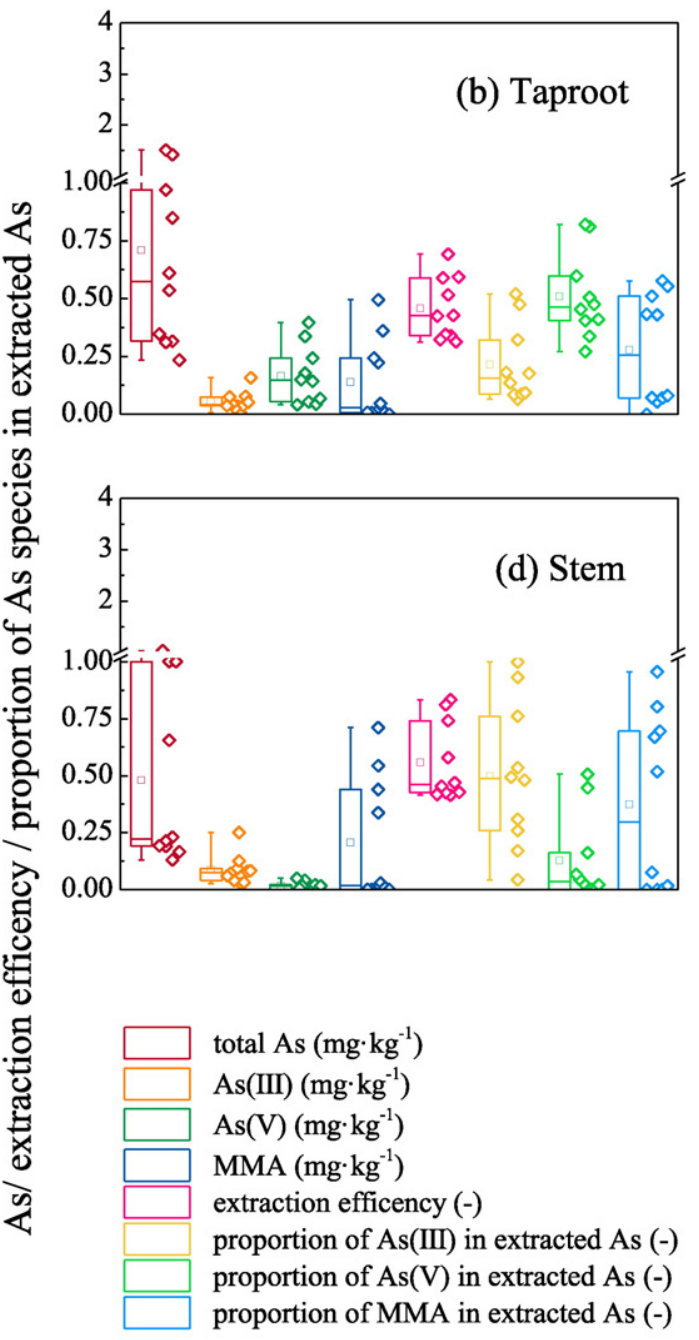

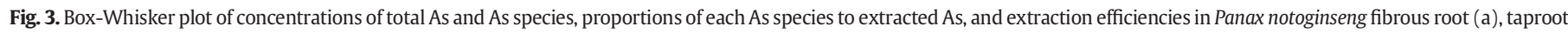
(b), rhizome (c), stem (d), and leaf (e) samples $(n=10)$, Diamonds represent data points and squares represent the average values. 
et al., 2015; Su et al., 2010). These results were in agreement with previous studies on plants grown in pots (Lin et al., 2015; Yan et al., 2012). Although As(III) concentrations had no obvious change during its upward transport in the plant body, the proportion of As(III) in extracted As gradually increased from around $20 \%$ in the root to roughly $50 \%$ in the stems. The average concentration of As(III) in the leaves ( $0.25 \mathrm{mg} \mathrm{kg}^{-1}$ ) was higher than in other tissues suggesting that $\mathrm{As}$ (III) is readily transferred from the root to the leaves (Kumar et al., 2015; Su et al., 2010). The average concentration of As(V) gradually decreased from the root $\left(0.16 \mathrm{mg} \mathrm{kg}^{-1}\right)$ to the stem and leaves (0.017 $\mathrm{mg} \mathrm{kg}^{-1}$ and $0.097 \mathrm{mg} \mathrm{kg}^{-1}$, respectively) revealing difficult translocation (Kumar et al., 2015; Su et al., 2010), and effective reduction by As(V) reductase (Yan et al., 2012).

Monomethylarsonic acid in P. notoginseng was identified (Fig. 3) in contrast to previous pot experiments (Lin et al., 2015; Yan et al., 2012). The average values of MMA concentration were around $0.3 \mathrm{mg} \mathrm{kg}^{-1}$ in the rhizome and stem, and was $0.2 \mathrm{mg} \mathrm{kg}^{-1}$ in the leaves (Fig. 3). Although MMA concentrations were lower than the detectable level in a few plant tissue samples, the high concentration and the proportion of MMA in some $P$. notoginseng samples indicated that As methylation occurred. Organic As was previously identified in $P$. notoginseng in a study of As species in various Chinese herbal medicines (Liu et al., 2013), and in Crupina vulgaris and Typha latifolia grown in highly polluted mining areas (Larios et al., 2012). Moreover, Wei et al. reported that eight plant species growing in an old antimony mine had the ability of As methylation (Wei et al., 2015). Organic As has barely been identified in plants when growth under greenhouse in media supplemented with inorganic As, suggesting that As methylation usually occurs under field conditions.

\subsection{Effect of As toxic stress on As reduction and methylation in the root}

Effect of As toxic stress on As reduction and methylation in the root of $P$. notoginseng was evaluated. The concentration of phosphoric acidextracted As in the soil as a function of the proportion of As species to extracted As in the root of $P$. notoginseng was found to directly and explicitly reveal effect of As toxic stress (Fig. 4). In the fibrous root, the proportion of $\mathrm{As}(\mathrm{V})$ to extracted As showed a significant negative correlation ( $\mathrm{p}<0.05, \mathrm{R}=0.74$ ) with phosphoric acid-extracted As under low As toxic stress (less than average value of phosphoric acidextracted As $\sim 15 \mathrm{mg} \mathrm{kg}^{-1}$ ) (Fig. 4a). In the taproot, the relationship between the proportion of MMA in extracted As and phosphoric acidextracted As was not significant under low As toxic stress, however, the proportion of MMA significantly increased with the increasing concentration of phosphoric acid-extracted As. The general pathway of As metabolism requires the production of organic As via the reduction of As(V) to As(III) and subsequent methylation (Meharg and HartleyWhitaker, 2002), thus the reduction of As(V) to As(III) leads to an indirect increase in MMA. In this study, methylation was the possible reason that the proportion of As(III) remained stable $\left(0.06-0.37 \mathrm{mg} \mathrm{kg}^{-1}\right)$ with the decreasing concentration of As(V) (Fig. 4a). Under high As toxic stress, the trend of As species transformation changed. The low reduction of $\mathrm{As}(\mathrm{V})$ led to decreased proportions of $\mathrm{As}(\mathrm{III})$ and MMA in the fibrous root. In the taproot, As reduction and methylation followed the same trend under low and high As toxic stress (Fig. 4b).

The reduction of As(V) to As(III) has been previously demonstrated in plants (Kumar et al., 2015; Su et al., 2010). Various antioxidant enzymes such as superoxide dismutase (SOD), peroxidase (POX), catalase (CAT), and nonenzymatic antioxidants (glutathione, ascorbate, and tochopherol) (Sharma, 2013) play a key role in the reduction process, which is stimulated as a stress response against As (Meharg and Hartley-Whitaker, 2002). In As non-hyperaccumulating plants, antioxidants trap As in the vacuole which is involved in the detoxification of As (Pickering et al., 2000; Schmoger et al., 2000). A previous pot study reported that $P$. notoginseng grown in soils with low As levels contained As(III), but no As(V), while those grown in soils with high As levels
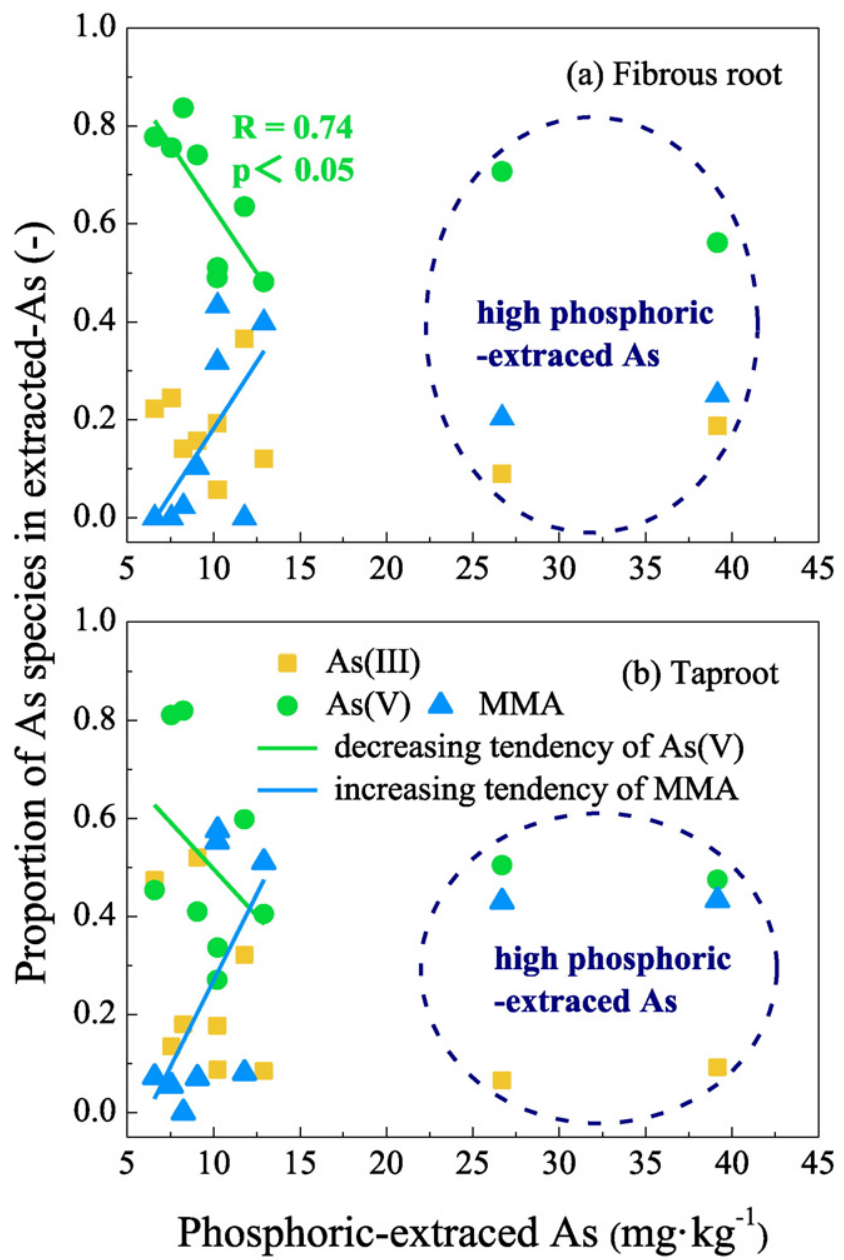

Fig. 4. Proportion of As species to extracted As versus phosphoric acid-extracted As in the fibrous root (a) and taproot (b) of Panax notoginseng.

contained both As(III) and As(V) (Yan et al., 2012). Because of the decrease in CAT activity at high As concentrations in the soil, $\mathrm{As}(\mathrm{V})$ reduction was suppressed (Yan et al., 2012)., although the activities of SOD and POX increased with the increasing As concentration of soil were observed (Yan et al., 2012), the facilitated $\mathrm{As}(\mathrm{V})$ reduction under low As toxic stress was missed in pot study due to the lack of As concentration gradient relative to our study under field conditions.

A previous review (Zhao et al., 2013) suggested that plants lack the ability of As methylation. Small proportions of methylated As species in terrestrial plants were collected either under fields or under controlled environmental conditions (Koch et al., 2000; Kuehnelt et al., 2000; Lomax et al., 2012; Meharg and Hartley-Whitaker, 2002; Raab et al., 2007; Xu et al., 2008; Zhao et al., 2006). In our study, however, unlike those plants grown in organic As-contaminated soils, MMA in the root of $P$. notoginseng was not derived from the soil. It indicated that the production of organic As occurred in the plant body (Wei et al., 2015). Although the underlying mechanisms of As(III) methylation in the root of $P$. notoginseng remain unclear, MMA concentration was related to As(III) concentration derived from absorbed-As(V). Therefore, similar to $\mathrm{As}(\mathrm{V})$ reduction, As(III) methylation was promoted by As toxic stress, but was impeded by high As concentrations in the soil.

\subsection{Arsenic translocation from the root to the rhizome}

In this study, the trend of As translocation from the taproot to the rhizome was clear, in contrast to the effect of As toxic stress on As reduction and methylation in plant tissues, except for the root, that were not obvious (data not shown), probably due to the long intermediate 
process, plant genotypes (Li et al., 2009; Liu et al., 2006; Norton et al., 2009), and planting conditions (Arao et al., 2009; Liu et al., 2006; Xu et al., 2008). The concentration of total As and As species in the rhizome versus the concentration of total As in the taproot was found to illustrate this trend (Fig. 5). A highly significant positive correlation was observed ( $p<0.01, R=0.90$ ) between total As in the taproot and total As in the rhizome (Fig. 5) revealing the easy As translocation from the root to the rhizome under As toxic stress. Moreover both As(III) and MMA showed highly significant correlation with total As in the taproot ( $p<0.01, \mathrm{R}$ close to 0.80 ) (Fig. 5), indicating the translocation of As(III) and MMA to the rhizome under As toxic stress. However, the relationship between total As in the taproot and $\mathrm{As}(\mathrm{V})$ in the rhizome was not significant, suggesting that $\mathrm{As}(\mathrm{V})$ translocation was insensitive under As toxic stress. In brief, the translocation of total As, As(III), and MMA from the root to the rhizome was a response to As toxic stress.

The proportions of As(III) and MMA were greater than those of $\mathrm{As}(\mathrm{V})$ in the stem, whereas the opposite pattern was observed in the rhizomes (Fig. 3c and d), suggesting a rapid upward translocation of As(III) and MMA from the rhizome to the stem. Although As translocation from the rhizome to the stem did not exhibit a similar As toxic stress expression, As(III) and MMA rapid upward translocation conformed to the trend of As species translocation in plants (Kumar et al., 2015). The proportion of $\mathrm{As}(\mathrm{V})$ in the leaves (22.6\%) was roughly two times higher than that in the stem (12.7\%) (Fig. 3d and e) suggesting that As(III) or MMA may be converted to $\mathrm{As}(\mathrm{V})$ in the leaves, after which it most likely produced As(III) and MMA via reduction and methylation, respectively (Wei et al., 2015).

The translocation of As species highly depends on plant species (Sheppard, 1992), and thus different studies have reached different conclusions. The generally accepted viewpoints are as follows: (1) inorganic As is more easily translocated than the As-phytochelatin complex due to As-phytochelatin low efflux in the vacuole (Liu et al., 2010; Raab et al., 2007); (2) As(III)-GSH enhances both As(III) efflux and root-toshoot translocation (Bleeker et al., 2006; Huang et al., 2008; Tripathi et al., 2007); and (3) MMA and DMA, especially the latter, has greater upward translocation than inorganic As (Li et al., 2009; Raab et al., 2007). In this study, As species translocation from the root to the rhizome was relatively high for MMA and $\mathrm{As}(\mathrm{III})$, and low for $\mathrm{As}(\mathrm{V})$, which was in agreement with the universal trends. Moreover, new characteristics of As species translocation were identified in this field study, including the rapid upward translocation and As toxic stress response of As(III) and MMA. However, the underlying mechanisms remain unclear and further investigation is needed.

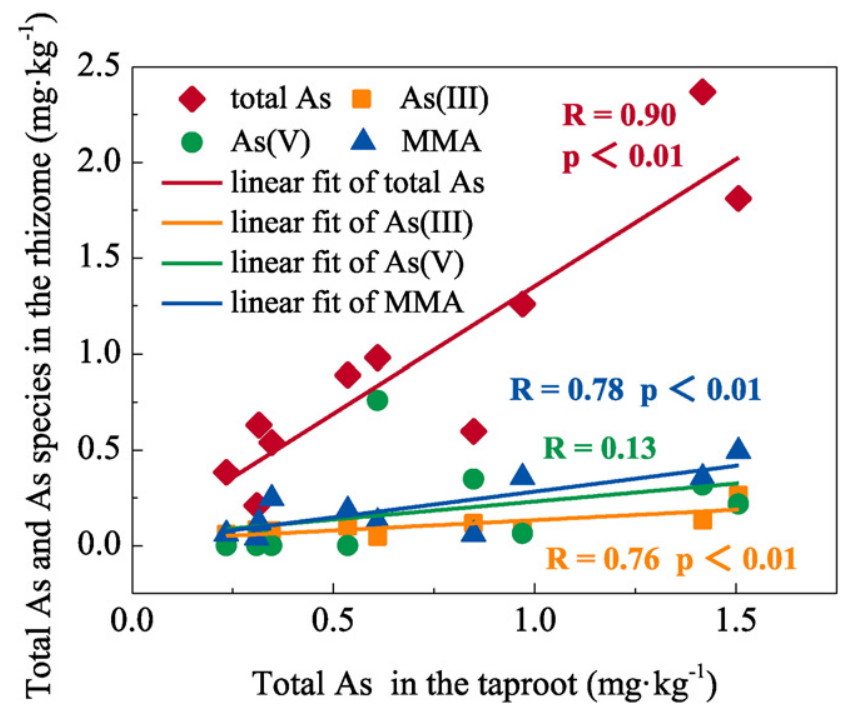

Fig. 5. Total As and As species in the rhizome of Panax notoginseng versus total As in the taproot.

\section{Conclusions}

This study aimed to determine As species in the soil and plant tissues using HPLC-HG AFS and explain As reduction, methylation, and translocation in P. notoginseng grown under field conditions in As-contaminated soils. Except for $\mathrm{As}(\mathrm{V})$, the major specie possibly absorbed by P. notoginseng, As(III) and MMA were also identified in plant tissues, suggesting that $\mathrm{As}(\mathrm{V})$ could be reduced and subsequently methylated in the plant body, mainly in the root. Arsenic(V) reduction and As(III) methylation in the root were promoted by low As toxic stress, but impeded by high As toxic stress. Both As(III) and MMA could rapidly translocate upwards in the plant body. In addition, the translocation of total As, As(III), and MMA translocation from the root to the rhizome was related to As toxic stress. Thus, this study provides new insights into the detoxification mechanism of $P$. notoginseng under As stress and could be beneficial to the control of As during cultivation.

\section{Acknowledgements}

The study is financially supported by the National Natural Science Foundation of China (Grant No. 21267024), Science and Technology Projects for Youth of Yunnan Provincial (Grant No. 2014FD063), and Innovative Talent Training Project of Yunnan Province (Grant No. 2014HB059 and 2015HC025).

\section{References}

Arao, T., Kawasaki, A., Baba, K., Mori, S., Matsumoto, S., 2009. Effects of water management on cadmium and arsenic accumulation and dimethylarsinic acid concentrations in Japanese rice. Environ. Sci. Technol. 43, 9361-9367.

Bleeker, P.M., Hakvoort, H.W., Bliek, M., Souer, E., Schat, H., 2006. Enhanced arsenate reduction by a CDC25-like tyrosine phosphatase explains increased phytochelatin accumulation in arsenate-tolerant Holcus lanatus. Plant J. 45, 917-929.

Burlo, F., Guijarro, I., Carbonell-Barrachina, A.A., Valero, D., Martinez-Sanchez, F., 1999. Arsenic species: effects on and accumulation by tomato plants. J. Agric. Food Chem. 47, 1247-1253.

Campbell, K.M., Malasarn, D., Saltikov, C.W., Newman, D.K., Hering, J.G., 2006. Simultaneous microbial reduction of iron(III) and arsenic(V) in suspensions of hydrous ferric oxide. Environ. Sci. Technol. 40, 5950-5955.

Cui, X.M., Lei, S.W., 2002. Panax notoginseng GAP cultivation techniques. Yunnan Science and Technology Press, Kunming (in Chinese).

Feng, R.W., Wang, X., Wei, C.Y., Tu, S., 2015. The accumulation and subcellular distribution of arsenic and antimony in four fern plants. Int. J. Phytoremediation 17, 348-354.

Fitz, W.J., Wenzel, W.W., 2002. Arsenic transformations in the soil-rhizosphere-plant system: fundamentals and potential application to phytoremediation. J. Biotechnol. 99 259-278.

Guo, H.B., Cui, X.M., An, N., Cai, G.P., 2010. Sanchi ginseng (Panax notoginseng (Burkill) F. H. Chen) in China: distribution, cultivation and variations. Genet. Resour. Crop. Evol. 57, 453-460.

Huang, Z.C., Chen, T.B., Lei, M., Liu, Y.R., Hu, T.D., 2008. Difference of toxicity and accumulation of methylated and inorganic arsenic in arsenic-hyperaccumulating and -hypertolerant plants. Environ. Sci. Technol. 42, 5106-5111.

Kaise, T., Fukui, S., 1992. The chemical form and acute toxicity of arsenic compounds in marine organisms. Appl. Organomet. Chem. 6, 155-160.

Koch, I., Wang, L.X., Ollson, C.A., Cullen, W.R., Reimer, K.J., 2000. The predominance of inorganic arsenic species in plants from Yellowknife, Northwest Territories, Canada. Environ. Sci. Technol. 34, 22-26.

Kuehnelt, D., Lintschinger, J., Goessler, W., 2000. Arsenic compounds in terrestrial organisms. IV. Green plants and lichens from an old arsenic smelter site in Austria. Appl. Organomet. Chem. 14, 411-420.

Kumar, S., Dubey, R.S., Tripathi, R.D., Chakrabarty, D., Trivedi, P.K., 2015. Omics and biotechnology of arsenic stress and detoxification in plants: current updates and prospective. Environ. Int. 74, 221-230.

Larios, R., Fernandez-Martinez, R., Lehecho, I., Rucandio, I., 2012. A methodological approach to evaluate arsenic speciation and bioaccumulation in different plant species from two highly polluted mining areas. Sci. Total Environ. 414, 600-607.

Li, R.Y., Stroud, J.L., Ma, J.F., McGrath, S.P., Zhao, F.J., 2009. Mitigation of arsenic accumulation in rice with water management and silicon fertilization. Environ. Sci. Technol. 43, 3778-3783.

Lin, L.Y., Yan, X.L., Liao, X.Y., Zhang, Y.X., Ma, X., 2015. Arsenic accumulation in Panax notoginseng monoculture and intercropping with Pteris vittata. Water Air Soil Pollut. 226.

Liu, W.J., Zhu, Y.G., Hu, Y., Williams, P.N., Gault, A.G., Meharg, A.A., Charnock, J.M., Smith, F.A., 2006. Arsenic sequestration in iron plaque, its accumulation and speciation in mature rice plants (Oryza sativa L.). Environ. Sci. Technol. 40, 5730-5736.

Liu, W.J., Wood, B.A., Raab, A., McGrath, S.P., Zhao, F.J., Feldmann, J., 2010. Complexation of arsenite with phytochelatins reduces arsenite efflux and translocation from roots to shoots in Arabidopsis. Plant Physiol. 152, 2211-2221. 
Liu, X.J., Zhao, Q.L., Sun, G.X., Williams, P., Lu, X.J., Cai, J.Z., Liu, W.J., 2013. Arsenic speciation in Chinese Herbal Medicines and human health implication for inorganic arsenic. Environ. Pollut. 172, 149-154.

Lomax, C., Liu, W.J., Wu, L., Xue, K., Xiong, J., Zhou, J., McGrath, S.P., Meharg, A.A., Miller, A.J., Zhao, F.J., 2012. Methylated arsenic species in plants originate from soil microorganisms. New Phytol. 193, 665-672.

Ma, L.Q., Komar, K.M., Tu, C., Zhang, W.H., Cai, Y., Kennelley, E.D., 2001. A fern that hyperaccumulates arsenic - A hardy, versatile, fast-growing plant helps to remove arsenic from contaminated soils. Nature 409, 579-579.

Ma, J., Guo, H.M., Lei, M., Zhou, X.Y., Li, F.L., Yu, T., Wei, R.F., Zhang, H.Z., Zhang, X., Wu, Y., 2015. Arsenic adsorption and its fractions on aquifer sediment: effect of $\mathrm{pH}$, arsenic species, and iron/manganese minerals. Water Air Soil Pollut. 226.

Marin, A.R., Pezeshki, S.R., Masschelen, P.H., Choi, H.S., 1993. Effect of dimethylarsenic acid (DMAA) on growth, tissue arsenic, and photosynthesis of rice plants. J. Plant Nutr. 16 865-880.

McGrath, S.P., Zhao, F.J., 2003. Phytoextraction of metals and metalloids from contaminated soils. Curr. Opin. Biotechnol. 14, 277-282.

Meharg, A.A., 1994. Integrated tolerance mechanisms - constitutive and adaptive plantresponses to elevated metal concentrations in the environment. Plant Cell Environ. 17, 989-993.

Meharg, A.A., Hartley-Whitaker, J., 2002. Arsenic uptake and metabolism in arsenic resistant and nonresistant plant species. New Phytol. 154, 29-43.

Ng, T.B., 2006. Pharmacological activity of sanchi ginseng (Panax notoginseng). J. Pharm. Pharmacol. 58, 1007-1019.

Norton, G.J., Islam, M.R., Deacon, C.M., Zhao, F.J., Stroud, J.L., McGrath, S.P., Islam, S. Jahiruddin, M., Feldmann, J., Price, A.H., Meharg, A.A., 2009. Identification of low inorganic and total grain arsenic rice cultivars from Bangladesh. Environ. Sci. Technol. 43 6070-6075.

Pickering IJ., Prince, R.C., George, M.J., Smith, R.D., George, G.N., Salt, D.E., 2000. Reduction and coordination of arsenic in Indian mustard. Plant Physiol. 122, 1171-1177.

Pizarro, I., Gomez, M., Camara, C., Palacios, M.A., 2003. Arsenic speciation in environmental and biological samples - extraction and stability studies. Anal. Chim. Acta 495, $85-98$.

Raab, A., Williams, P.N., Meharg, A., Feldmann, J., 2007. Uptake and translocation of inorganic and methylated arsenic species by plants. Environ. Chem. 4, 197-203.

Ramirez-Andreotta, M.D., Brusseau, M.L., Artiola, J.F., Maier, R.M., 2013. A greenhouse and field-based study to determine the accumulation of arsenic in common homegrown vegetables grown in mining-affected soils. Sci. Total Environ. 443, 299-306.

Ravenscroft, P., Brammer, H., Richards, K., 2009. Arsenic pollution: A global synthesis. Wiley-Blackwell.

Ruiz-Chancho, M.J., Lopez-Sanchez, J.F., Schmeisser, E., Goessler, W., Francesconi, K.A, Rubio, R., 2008. Arsenic speciation in plants growing in arsenic-contaminated sites. Chemosphere 71, 1522-1530.

Schmoger, M.E., Oven, M., Grill, E., 2000. Detoxification of arsenic by phytochelatins in plants. Plant Physiol. 122, 793-801.

Schoof, R.A., Yost, L.J., Eickhoff, J., Crecelius, E.A., Cragin, D.W., Meacher, D.M., Menzel, D.B 1999. A market basket survey of inorganic arsenic in food. Food Chem. Toxicol. 37 839-846.

Sharma, I., 2013. Arsenic stress in plants: An inside story, crop improvement. Springer US, pp. 379-400.
Sheppard, S.C., 1992. Summary of phytotoxic levels of soil arsenic. Water Air Soil Pollut. 64, 539-550.

Sousa-Ferreira, H., Matos-Reyes, M.N., Cervera, M.L., Costa-Ferreira, S.L., de la Guardia, M., 2010. Screening of toxic inorganic arsenic apecies in garlic (Allium sativum L.). Food Anal. Methods 4, 447-452.

Su, Y.H., McGrath, S.P., Zhao, F.J., 2010. Rice is more efficient in arsenite uptake and translocation than wheat and barley. Plant Soil 328, 27-34.

Tong JT , Guo, H.M. Wei, C, 2014. Arsenic contamination of the soil-wheat system irrigated with high arsenic groundwater in the Hetao Basin, Inner Mongolia, China. Sci. Total Environ. 496, 479-487.

Tripathi, R.D., Srivastava, S., Mishra, S., Singh, N., Tuli, R., Gupta, D.K., Maathuis, F.J.M., 2007. Arsenic hazards: strategies for tolerance and remediation by plants. Trends Biotechnol. 25, 158-165

Tu, C., Ma, L.Q., Zhang, W., Cai, Y., Harris, W.G., 2003. Arsenic species and leachability in the fronds of the hyperaccumulator Chinese brake (Pteris vittata L.). Environ. Pollut. $124,223-230$.

Tufano, K.J., Reyes, C., Saltikov, C.W., Fendorf, S., 2008. Reductive processes controlling arsenic retention: revealing the relative importance of iron and arsenic reduction. Environ. Sci. Technol. 42, 8283-8289.

Wang, J., Zhao, F.J., Meharg, A.A., Raab, A., Feldmann, J., McGrath, S.P., 2002. Mechanisms of arsenic hyperaccumulation in Pteris vittata. Uptake kinetics, interactions with phosphate, and arsenic speciation. Plant Physiol. 130, 1552-1561.

Wei, C.Y., Ge, Z.F., Chu, W.S., Feng, R.W., 2015. Speciation of antimony and arsenic in the soils and plants in an old antimony mine. Environ. Exp. Bot. 109, 31-39.

Wenzel, W.W., Kirchbaumer, N., Prohaska, T., Stingeder, G., Lombi, E., Adriano, D.C., 2001. Arsenic fractionation in soils using an improved sequential extraction procedure. Anal. Chim. Acta 436, 309-323.

Williams, P.N., Raab, A., Feldmann, J., Meharg, A.A., 2007. Market basket survey shows elevated levels of as in South Central US processed rice compared to California: consequences for human dietary exposure. Environ. Sci. Technol. 41, 2178-2183.

Wuilloud, R.G., Kannamkumarath, S.S., Caruso, J.A., 2004. Speciation of essential and toxic elements in edible mushrooms: size-exclusion chromatography separation with online UV-inductively coupled plasma mass spectrometry detection. Appl. Organomet. Chem. 18, 156-165.

Xu, X.Y., McGrath, S.P., Meharg, A.A., Zhao, F.J., 2008. Growing rice aerobically markedly decreases arsenic accumulation. Environ. Sci. Technol. 42, 5574-5579.

Yan, X.L., Lin, L.Y., Liao, X.Y., Zhang, W.B., 2012. Arsenic accumulation and resistance mechanism in Panax notoginseng, a traditional rare medicinal herb. Chemosphere 87, 31-36.

Zhao, Y.Q., 2015. Panax notoginseng (Burk.) F.H. Chen (Sanqi, Notoginseng), Dietary Chinese Herbs. Springer Vienna, pp. 185-193.

Zhao, R., Zhao, M.X., Wang, H., Taneike, Y., Zhang, X.R., 2006. Arsenic speciation in moso bamboo shoot - A terrestrial plant that contains organoarsenic species. Sci. Total Environ. 371, 293-303.

Zhao, F.J., Zhu, Y.G., Meharg, A.A., 2013. Methylated arsenic species in rice: geographical variation, origin, and uptake mechanisms. Environ. Sci. Technol. 47, 3957-3966.

Zhao, D., Li, H.B., Xu, J.Y., Luo, J., Ma, L.O., 2015. Arsenic extraction and speciation in plants: method comparison and development. Sci. Total Environ. 523, 138-145. 